\title{
MACROECONOMIC IMBALANCES IN EURO AND NON-EURO AREA MEMBER STATES
}

\author{
Daniela Bobeva*, Atanas Atanasov**
}

\begin{abstract}
Summary
This paper examines the macroeconomic imbalances in the euro area countries in comparison with the non-euro area countries based on the set of indicators in the Scoreboard that is part of the Macroeconomic Imbalance Procedure (MIP), introduced in 2011.

While the aim of the new alert mechanism is to identify potential risks this study goes further in measuring the level of risks by the scope of the deviation from the established thresholds. For this purpose an Integral Macroeconomic Imbalance Indicator (IMII) is constructed. It serves for comparing the level of imbalances between the countries in preand post- crisis period. The composed IMII indicates a tangible reduction in the scale of imbalances as compared to the pre-crisis period but the divergence between the countries enlarges. The results undermine the assumptions that the countries in the euro area will show fewer imbalances as compared to the countries outside of the monetary union. Based on the dynamics of IMII it could be assumed that maintaining the macroeconomic framework within the thresholds is necessary but not sufficient to prevent future crisis. The results further question the ability of the alert mechanism to identify the sources of a future crisis.
\end{abstract}

Key words: Macroeconomic Imbalances, Macroeconomic Imbalances Procedure scoreboard, EU financial sector, Economic reforms, Six pack.

JEL: E61, E66, H12

\section{Introduction}

The recent reforms in the European economic governance framework add to the Stability and Growth pact requirements for establishing a new macroeconomic surveillance mechanism for both euro area and non-euro area countries. The early identification and the prevention of imbalances are of vital importance in a monetary union due to the limitations they impose on the tools available

\footnotetext{
* Assoc. Prof. Dr. Daniela Bobeva, Economic Research Institute, Bulgarian Academy of Science e-mail: d.bobeva@iki.bas.bg

${ }^{* *}$ Chief Assistant Prof. Dr. Atanas Atanasov, Department: Statistics and Econometrics, Faculty Applied Informatics and Statistics, University of National and World Economy, e-mail: atanassov@unwe.bg
} 
to economic policymaking. The recent reforms in the European economic governance framework strengthened the Stability and Growth Pact requirements by establishing a new macroeconomic surveillance mechanism for both euro area and non-euro area countries. The Macroeconomic Imbalances Procedure includes a new alert mechanism and in-depth analysis that serve for that purpose. The Scoreboard shows which countries exceed the threshold of each indicator and in substance this is the warning for a macroeconomic imbalance. Whether those new instruments are sufficient to correctly measure the imbalances and predict the crisis remains an open question. Furthermore, the prevention arm of the new mechanism is also questionable, given that most of the indicators cannot be corrected by government policies. The set of indicators play different role in the macroeconomic framework but they are not given specific weights in the Scoreboard and are treated as equally important for the accumulation of imbalances. The choice of the indicators is also not backed by sufficient arguments. For example, the indicator for financial sector fails to exhibit the complexity of financial sector stability. The data shows exposes financial stability in countries with severe problems of financial sector. One of the weaknesses of the Scoreboard is that it does not assess the scope of deviation from the thresholds. The purpose of this paper is to develop an instrument that would overcome one of the weaknesses of the Scoreboard the one that it fails to measure how serious any imbalance is. That is why it is suggested to measure the scope of the deviation by constructing a new indicator. The new indicator is calculated for all euro area and non-euro area countries and the comparison produces some results that the Scoreboard does not show directly. To attain a precise measurement and to deepen the analysis of the macroeconomic imbalances may be a solid argument for the usage of the constructed new indicator.

\section{MIP's alert mechanism}

Early identification and prevention of imbalances is important for all EU member states. The reform included a set of tools that the conventional theory had not invented. In this case the policy decision went ahead of the theory.

The scoreboard for the surveillance of macroeconomic imbalances under the MIP is part of the MIP's alert mechanism. It consists of a scoreboard with 14 headline indicators covering external and internal macroeconomic imbalances. The scoreboard includes both stock and flow indicators with indicative upper and lower alert thresholds which are differentiated for euro and non-euro area Member States. (Figure 1) Some authors, Csortos and Szalai (2013) call for different thresholds for euro area and non-euro area countries for all the indicators. They examine how the indicators perform in the case of ten new member states that joined the EU in 2004. 
Figure 1: The MIP Scoreboard Indicators

Three-year backward moving average of the current account balance as percent of GDP

$+6 \%$ of GDP and $-4 \%$ of GDP

Net international investment position as percent of GDP

$-35 \%$ of GDP

Five-year percentage change of export market shares measured in values

$-6 \%$

Three-year percentage change in nominal unit labour cost

$+9 \%$ for euro area countries and

$+12 \%$ for non-euro area countries

Three-year percentage change of the real effective exchange rates based on HICP/CPI deflators, relative to 41 other industrial countries

$-/+5 \%$ for euro area countries and $-/+11 \%$ for non-euro area countries

Private sector debt (consolidated) in percent of GDP

$133 \%$ of GDP

Private sector credit flow in percent of GDP

$14 \%$ of GDP

Year-on-year changes in house prices relative to a Eurostat consumption deflator

$6 \%$

General government sector debt in percent of GDP $60 \%$ of GDP

Three-year backward moving average of unemployment rate

$10 \%$

Year-on-year changes in total financial sector liabilities

$16.5 \%$

Three-year change in percentage points of the activity rate (in p.p.)

$-0.2 \%$

Three-year change in percentage points of the long-term unemployment rate (in p.p.)

$-0.5 \%$

Three-year change in percentage points of the youth unemployment rate (in p.p.)

$+2 \%$

Note: Those are the indicators as of May 2016.

The reading of headline indicators is complemented by 25 auxiliary indicators such as economic growth, nominal and real convergence inside and outside the euro area, productivity developments, foreign and domestic investment, as well as sectorial developments, which affect GDP and current account performance. The initial screening of macroeconomic imbalances is mandated to the Alert 
Mechanism Report which identifies the Member States whose developments warrant further in-depth analysis to determine whether imbalances exist.

The nature of the imbalances and their gravity are subject to the follow-up indepth analysis country by country. Another vague issue is the criteria according to which the Member States that incur imbalances are selected for the in-depth analysis. Still, it remains unclear which of the scoreboard indicators have the highest weight when the EU makes assessment with regard to whether a Member State experiences serious imbalances. Those uncertainties of the application of the scoreboard need further attention having in mind the importance of the scoreboard in shaping market perceptions and the EU economic governance framework. This fact begs the question of how strong the imbalances should be in order to activate the procedure and cast a shadow over the transparency of applying the MIP criteria. The literature suggests many attempts to measure the risk of a crisis based on a complex criteria (Borio C., Drehmann M., 2009).

The obvious difficulty in constructing such indicators for macroeconomic imbalances is how to identify in a reliable way the build-up of the imbalances as they develop. There is a very fine line between what is "far" and "too far" from the reference value of the indicators. Moreover, to be useful for policy, any indicator has to identify the risk of future financial strains with a lead sufficient to allow the authorities to take remedial action (Borio and Lowe, 2002).

According to the current procedure the qualitative nature of the analysis gives a lot of flexibility in the interpretation of the EU authorities. In many cases the indepth analysis goes far from the qualitative indicators that may risk the confidence in the entire mechanism. That is why some criticism from some EU member states was already expressed (Hickey, R. and Kane, L. 2014). Not surprisingly for such a policy tool that encompasses so many functions in the EU economic governance framework, its main principles have faced criticism. The ECB has emphasized that the judgment element of the scoreboard, even if necessitated by the complexity of the economic imbalances and the difficulty to assess them only on the grounds of a matrix of indicators, creates uncertainty and room for broad interpretation.

A clear example of a misconnection between the Scoreboard and the in-depth conclusions is the case with Bulgaria. The starting point of the MIP is the Alert Mechanism Report which has to be based on the Scoreboard data. The report identifies countries for which a closer analysis (in-depth review) is deemed necessary. Although the Scoreboard showed diminishing macroeconomic imbalances for Bulgaria in the last two reports, including the fact that financial sector indicator value was within the limits, the country was included in the indepth analysis and in the corrective arm of the excessive imbalances procedure. 
There are no criteria and clarity for the linkage between the Scoreboard and the assigned levels of MIP of each country. In many cases the Scoreboard and the MIP conclusions are not linked which would make the whole process misleading. As part of the communication role of the scoreboard, the EU announces a ranking of sorts for the countries according to the level of risks for their economies. This public message itself may fuel the negative market perceptions about those countries, warning investors about the risks in those contexts, thus further deteriorating their economic situation. In order to strengthen the confidence in the MIP more quantitative and objective approaches are needed. Further fine tuning of the Scoreboard and the whole procedure should aim at better assessment of the gravity of the imbalances based on quantitative indicators. Also, a solid measurable construction is needed to be established between the Scoreboard and the in-depth review in order to avoid misinterpretations. The importance of the indicators for the accumulation of imbalances is different but the Scoreboard treats them equally. This weakness is partly compensated by the in-depth review but still there might be a way to rank them. The above possible changes would strengthen the credibility of the MIP.

\section{Measuring the scope of the imbalances}

Currently, the Scoreboard alerts in all cases when the threshold is exceeded. Though, there are many reasons to believe that not only the fact of but also the scope of deviation is important. That is why an indicator is constructed to estimate how large the deviations from the thresholds are. The assumption is that the larger the deviation the greater the risk is that the accumulation of imbalances will lead to a crisis: Integral Macroeconomic Imbalance Index (IMII). Integral Macroeconomic Imbalance Index (IMII) is based on an approach which assesses the behavior of the two groups of variables:

- The first group describes the external imbalances and the competitiveness of the country and includes the following 5 variables: (1) Current Account Balance as \% of GDP; (2) Net International Investment Position as \% of GDP; (3) Real Effective Exchange Rate, year-on-year percentage change; (4) Year-on-year percentage change in export market Shares and (5) Nominal ULC, year-on-year percentage change.

- The second group describes the internal imbalances of the economy and includes 6 variables: (1) Private Sector Debt (consolidated) as a percentage of GDP; (2) Private Sector Credit Flow (consolidated) as \% of GDP; (3) Year-on-year percentage change in Deflated House Price Index; (4) General 
Government Sector Debt as \% of GDP; (5) Year-on-year percentage change in Total Financial Sector Liabilities and (6) Unemployment Rate ${ }^{1 .}$

An indicator variable relating to indicator $i$ and country $j$ is denoted by $Y_{i}^{j}$ and the threshold for this indicator is denoted as $T_{i}^{j}$.

The first stage is to check if each variable remains within its threshold boundary or crosses the threshold. In the first situation, the indicator is zero, but if we are in the second situation, we need to compute the percentages that exceed the critical threshold (in absolute value). The formula is:

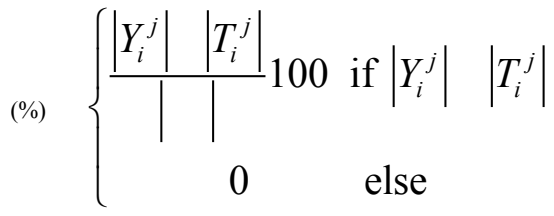

where $I_{i}^{j}(\%)$ is the percentages that exceed the critical threshold, $Y_{i}^{j}$ is the value of the related indicator and $T_{i}^{j}$ is the threshold for this indicator.

The second stage is to eliminate the effect of the scale. This is required because the different variables are measured on different scales and the variables have to be normalized. For this purpose we use the following max transformation:

$N_{i}^{j}=\frac{I_{i}^{j}(\%)}{I_{\max }}$, where $N_{i}^{j}$ is the normalized value and $I_{\max }$ is the maximum value of the variable.

IMII is calculated as an average of the individual indicators for every country.

The IMII is normalized between zero and one. If an economy is balanced, then the index will be equal to zero. If the economy is imbalanced, then the index will be close to one. The IMII can be used in two situations: (1) for a comparison between different countries and (2) to compare different periods of development.

One of the advantages of the indicator is that it integrates 14 indicators in one. The limitations of the indicator are related with its integrative character. It limits the impact of a large deviation of one indicator on the total size of the indicator. It has to be used in combination with qualitative assessment. Also it inherits the weakness of the Scoreboard that all indicators have equal weights.

We use the indicator to assess the scope of imbalances in two aspects: (i) the scope of imbalances at country level in order to identify which ones are more and less balanced economies; (ii) the dynamics of the imbalances over the eleven year period in order to see how the macroeconomic framework was impacted by the crisis.

\footnotetext{
1 The indicators for activity, youth and long-term unemployment rate will not lead to legal implications and flashes of the new employment indicators will not trigger further steps in the MIP. That is why we do not use them in constructing the Integral Macroeconomic Imbalance Index.
} 


\section{The crisis and imbalances}

The calculations of the integrated indicator (IMII) show that for the whole eleven years period the imbalances in the EU were significant while large divergence between the countries was sought (Attachment 1). Also the imbalances vary in the three crisis-related periods, pre-crisis, crisis and post-crisis period. The IMII was 0.15 in 2005 indicating very low level of imbalances. The highest value was in 2012 when the indicator reached 0.27 . In the post-crisis period the imbalances diminished rapidly and reached the pre-crisis levels in 2015.

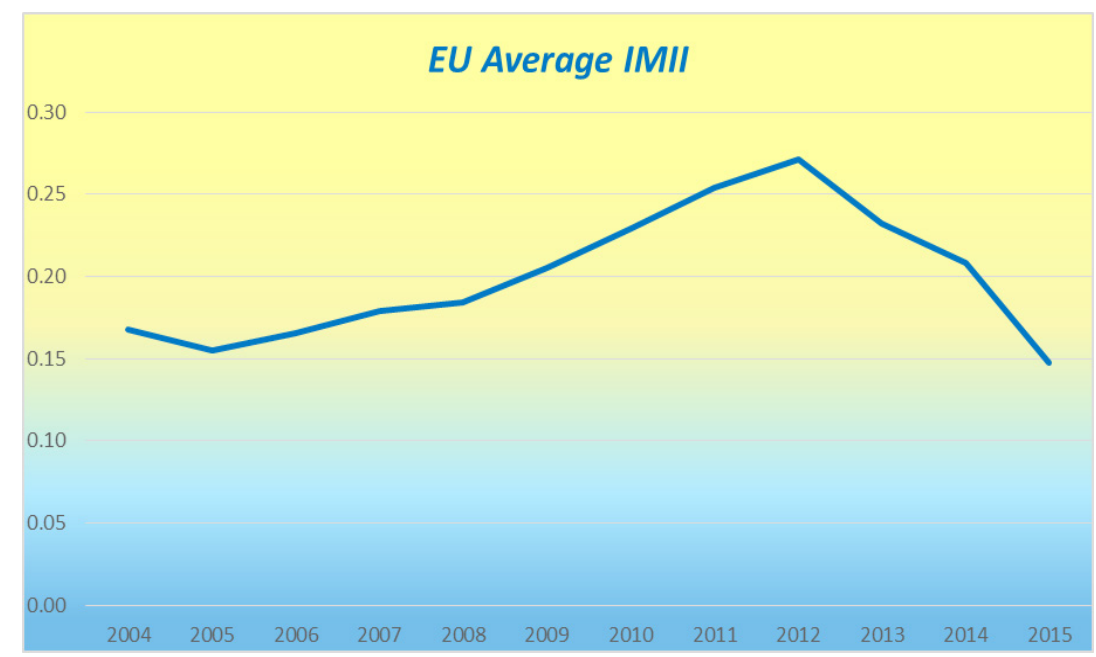

Decomposing the dynamics of all the EU member states into different groups of countries shows that a strong divergence is observed. Before the crisis the imbalances were larger in the EU catching-up economies as compared to the rest of the EU. The old EU member-states economies were significantly more balanced. The crisis helped the majority of the catching-up economies to reduce their imbalances while several euro area member states enlarged their imbalances and affected the entire euro area where the integral indicator jumped to the historically high levels. 


\section{IMII for catching up economies and the rest of EU (2004-2015)}

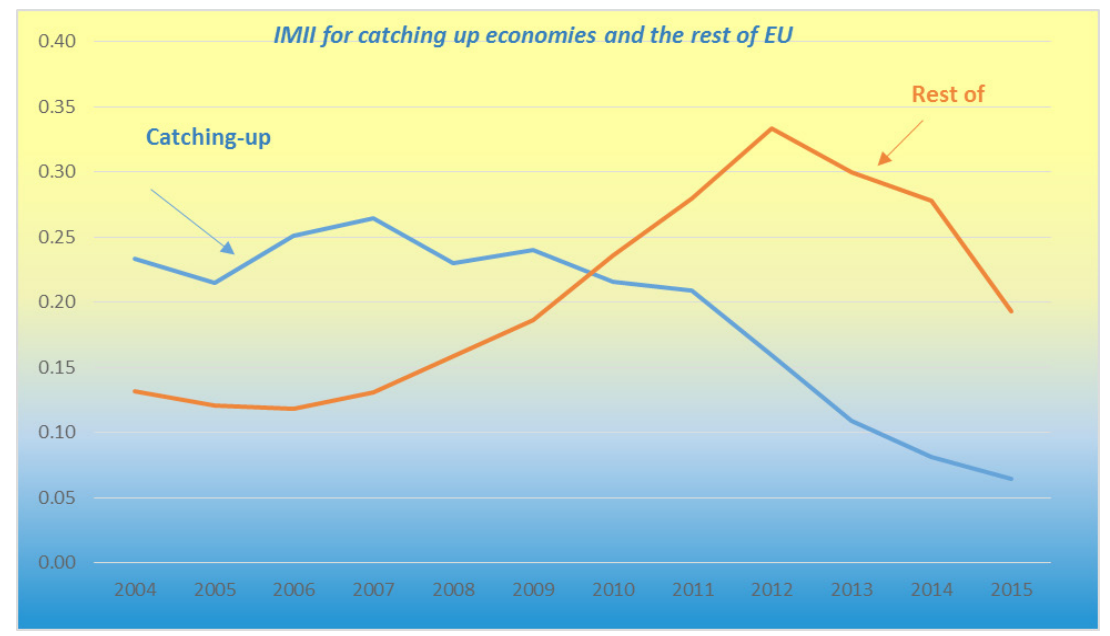

The IMII indicates that catching-up economies suffered the largest imbalances before the crisis which is associated with the strong economic growth driven in some of the countries by high credit growth and booming real estate markets. The slowing down of the economic growth helped to diminish the imbalances.

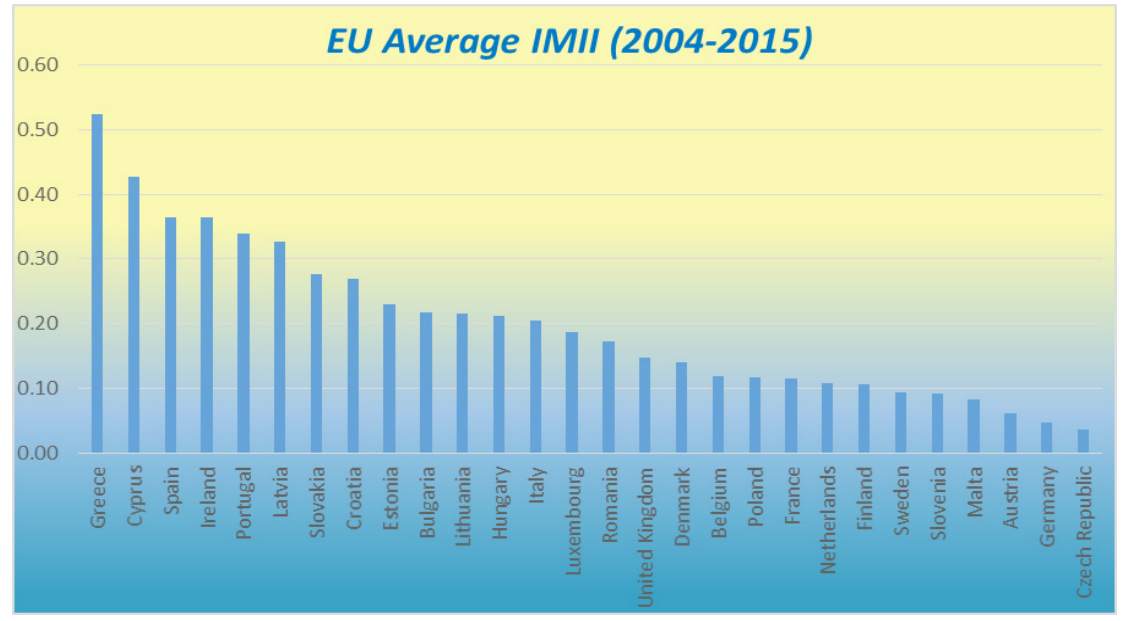

The best performers in terms of low imbalances for the entire EU were the Czech Republic, Germany, Austria, Malta, Sweden and Slovenia where the IMII was close to zero for the entire eleven years period and in average below 0.1. For those economies the crisis did not produce imbalances. For Estonia, Bulgaria, Romania, Slovakia and Poland the crisis helped winding up the imbalances while for Cyprus, Greece, Spain, Croatia the crisis strongly enlarged the imbalances. 
The observed eleven year period includes the pre-crisis, crisis and post-crisis periods which create the opportunity to test the relevance of the selected set of indicators in the Scoreboard for predicting the crisis. For many countries the crisis produced imbalances. This hypothesis may be tested analyzing the cases of the countries where the crisis was more severe and led to EU rescue measures. In spite of the different causes and implications of the crisis in each of those economies the macroeconomic imbalances followed very similar pattern: negligible imbalances from 2004 to 2008-2009 and rapid accumulation of imbalances after this period. It seems that after 2013 all those countries succeeded in diminishing their imbalances. There are some variations in this common pattern.

\section{IMII Greece, Cyprus, Spain, Ireland (2004-2015)}

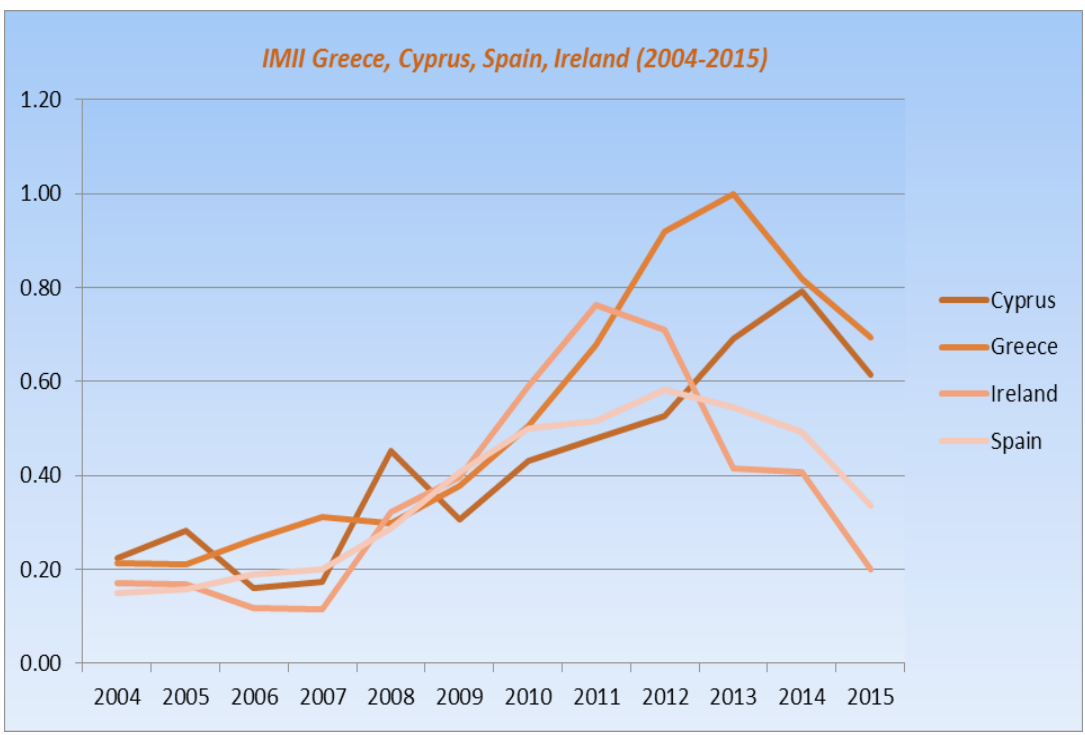

The macroeconomic imbalances in Greece started increasing after 2010 when the IMII reached 0.5 while before that its values were between 0.21 and 0.38 . Even if we do not use the composed indicator (IMII) the data for the scoreboard indicate that before 2010 most of the indicators were below the thresholds. The scoreboard as a complex of indicators failed to signal about the accumulation of imbalances that will cause such a deep crisis. Moreover, the IMF and the EU rescue packages were started in 2010 when the imbalances started enlarging. Even in 2015 Greece could not reach its pre-crisis levels of imbalances.

Ireland's scoreboard data suggests that during the pre-crisis period no substantial imbalances were accumulated. In 2010, however, the IMII reached 0.59. The largest imbalances occurred in 2011 when the IMII was 0.76 and the 
balances restored in 2014 and 2015 tending to reach the pre-crisis low levels of imbalances.

Cyprus's macroeconomic imbalances too accumulated during the crisis rather than before it. Once again in 2015 the imbalances were significant and the IMII was close to 0.40 . The Spanish economy did not reached the levels of imbalances of Greece and Cyprus. The IMII suggests clear path to their reduction but vulnerabilities still exist.

The overall data as well as for the four countries suggests that the Scoreboard as a complex of indicators failed to predict the upcoming crisis. Looking at the set as a whole may be misleading and may hide the accumulation of a single imbalance that may call for a crisis. This is one of the main problems of the Scoreboard: it assembles and gives equal weight to each indicator. It is more relevant to look at few stronger indicators than putting on an equal basis so many not well economically motivated indicators as an early warning system.

The scoreboard suggests that now the EU looks more balanced. This is also confirmed by the values of the IMII that reached in 2015 the lowest level since 2004. The concept of the Scoreboard is that a better economy is a more balanced economy - less exposed to risks of a crisis. But now being more balanced the EU economy is recovering too slowly and the slow growth is a major risk for vulnerability of the EU economy.

\section{Conclusions}

The composed IMII indicates a tangible reduction in the scale of imbalances as compared to the pre-crisis period in the non-euro area countries. An opposite pattern of imbalances is observed in most euro area countries where the imbalances increased since the beginning of the crisis. The best performers are the Czech Republic and Germany. The results undermine the assumptions that the euro area countries will exhibit fewer imbalances as compared to the countries outside of the monetary union. The divergence between the countries in the euro area enlarges. The most imbalanced countries before the crisis were Bulgaria and Estonia but no crisis occurred there and the imbalances quickly diminished. Surprisingly the imbalances in the countries where severe crisis occurred were less than those in Bulgaria and Estonia, namely Greece, Ireland and Spain. This undermines the capability of the new mechanism to predict the crisis. 


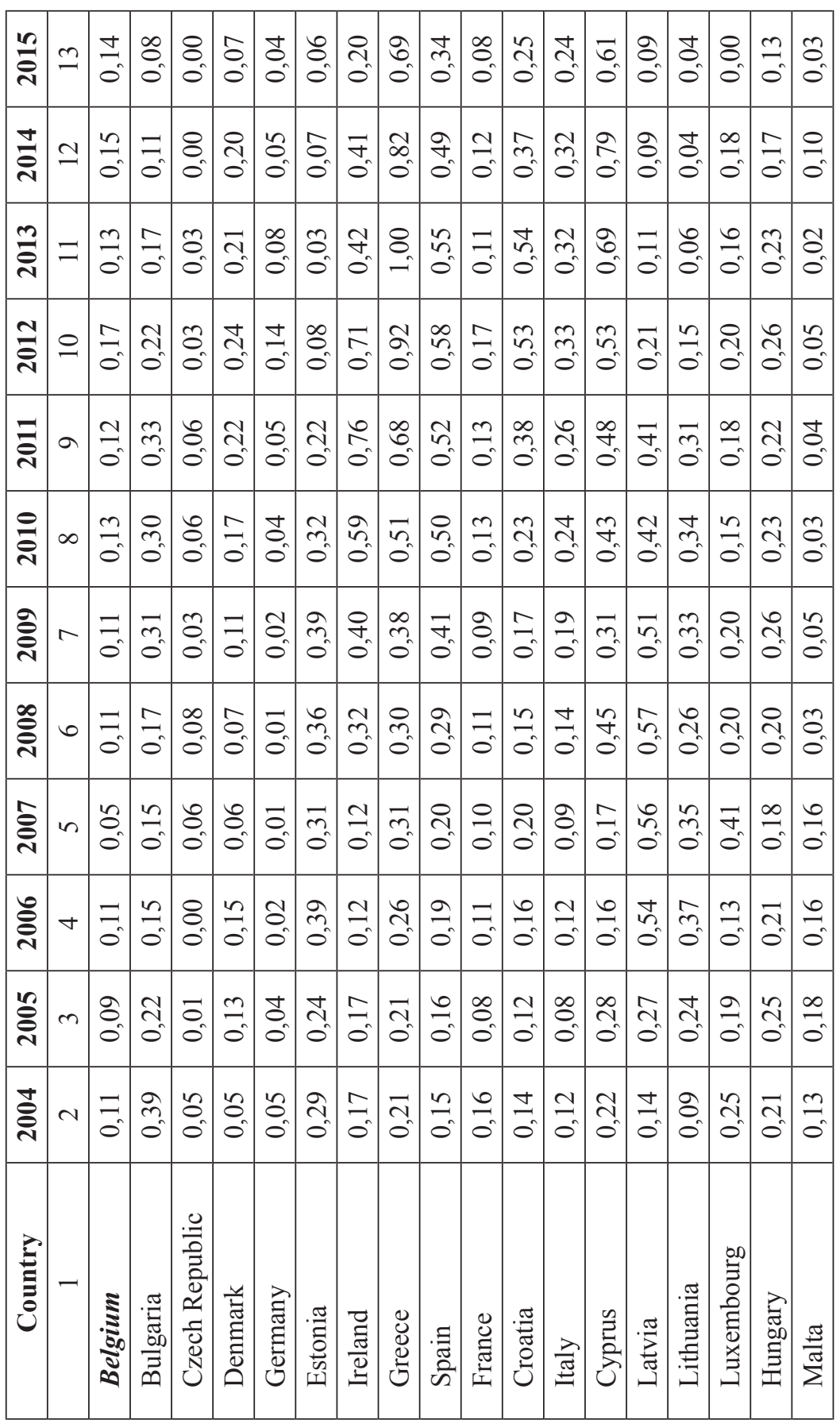




\begin{tabular}{|c|c|c|c|c|c|c|c|c|c|c|}
\hline 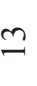 & $\begin{array}{l}\infty \\
0 \\
0 \\
0\end{array}$ & $\begin{array}{l}\infty \\
0 \\
0 \\
0\end{array}$ & $\begin{array}{l}n \\
0 \\
0\end{array} \mid$ & $\begin{array}{c}\stackrel{2}{0} \\
\tilde{0}\end{array}$ & $\begin{array}{l}n \\
0 \\
0\end{array}$ & $\begin{array}{l}0 \\
0 \\
0\end{array}$ & $\frac{\sim}{0}$ & $\underset{0}{ \pm}$ & $\begin{array}{l}\infty \\
0 \\
0 \\
0\end{array}$ & $\begin{array}{l}\infty \\
0 \\
0\end{array}$ \\
\hline$\simeq$ & $\overrightarrow{0}$ & $=$ & $\begin{array}{l}0 \\
0 \\
0\end{array}$ & $\begin{array}{l}O_{0} \\
\dot{f}_{\alpha}\end{array}$ & $\begin{array}{l}\mathbb{O}_{0} \\
0^{2}\end{array}$ & $\frac{m}{0}$ & $\begin{array}{c}0 \\
0 \\
0\end{array}$ & $\frac{n}{0}$ & $\begin{array}{l}\infty \\
0 \\
0 \\
0\end{array}$ & $\stackrel{0}{0}$ \\
\hline$=$ & $\begin{array}{c}0 \\
\stackrel{0}{0}\end{array}$ & $\stackrel{\sim}{\stackrel{1}{0}}$ & $\left|\begin{array}{l}\infty \\
0 \\
0 \\
0\end{array}\right|$ & $\begin{array}{l}\infty \\
\stackrel{+}{+} \\
0\end{array}$ & $\begin{array}{l}n \\
0 \\
0\end{array}$ & $\begin{array}{l}\tilde{N} \\
\tilde{o}\end{array}$ & $\begin{array}{l}0 \\
0 \\
0\end{array}$ & 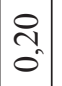 & $\frac{1}{0}$ & : \\
\hline 으 & $\frac{a}{0}$ & $\frac{n}{0}$ & $=$ & $\begin{array}{l}0 \\
n \\
0\end{array}$ & $\begin{array}{l}\infty \\
0 \\
0 \\
0\end{array}$ & 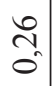 & $\frac{a}{0}$ & $\begin{array}{l}\tilde{N} \\
\tilde{O}\end{array}$ & $\frac{ \pm}{0}$ & $\frac{\infty}{0}$ \\
\hline$a$ & $\frac{m}{0}$ & $\begin{array}{l}\infty \\
0 \\
0\end{array}$ & $\stackrel{\simeq}{\simeq}$ & $\stackrel{\mathscr{\vartheta}}{\stackrel{\sigma}{0}^{\prime}}$ & $\begin{array}{l}\dot{0} \\
0^{\prime}\end{array}$ & $\stackrel{\sim}{\underset{0}{0}}$ & $\begin{array}{l}\vec{v} \\
0\end{array}$ & $\overrightarrow{\widetilde{N}}$ & $\begin{array}{l}0 \\
0 \\
0\end{array}$ & 亿2 \\
\hline$\infty$ & $\begin{array}{l}\infty \\
0 \\
0 \\
0\end{array}$ & $\begin{array}{l}\mathbb{O}_{0} \\
0^{\prime}\end{array}$ & $\begin{array}{l}\infty \\
0 \\
0\end{array} \mid$ & $\begin{array}{l}\infty \\
2 \\
0\end{array}$ & $\frac{m}{0}$ & $\hat{\sigma}_{0}$ & 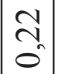 & $\begin{array}{c}\infty \\
0 \\
0\end{array}$ & $\frac{1}{0}$ & $\begin{array}{l}0 \\
\text { n. } \\
\text { on }\end{array}$ \\
\hline$r$ & $\begin{array}{l}\infty \\
0 \\
0 \\
0\end{array}$ & $\begin{array}{l}\mathbb{O}_{0} \\
0^{\prime}\end{array}$ & $\begin{array}{l}0 \\
0 \\
0\end{array} \mid$ & $\begin{array}{l}m \\
\tilde{0} \\
0\end{array}$ & $\begin{array}{c}\text { సે } \\
\text { ஸ́ }\end{array}$ & $\begin{array}{l}\mathbb{O}_{0} \\
0^{\prime}\end{array}$ & $\begin{array}{c}\hat{n} \\
\tilde{0}\end{array}$ & $\begin{array}{l}\infty \\
0 \\
0\end{array} \mid$ & $\frac{n}{0}$ & $\begin{array}{l}n \\
\tilde{n} \\
0\end{array}$ \\
\hline 6 & $\begin{array}{l}\circ \\
\stackrel{0}{0} \\
0\end{array}$ & $\begin{array}{l}\overrightarrow{0} \\
0^{\prime}\end{array}$ & $\exists$ & $\left|\begin{array}{l}0 \\
n \\
0\end{array}\right|$ & $\begin{array}{l}\overrightarrow{\hat{\sigma}} \\
\hat{0}\end{array}$ & $\begin{array}{l}\overline{0} \\
0\end{array}$ & $\begin{array}{l}m \\
\tilde{n} \\
0\end{array}$ & $\begin{array}{l}8 \\
0 \\
0\end{array}$ & $\mid \begin{array}{l}\infty \\
0 \\
0 \\
0\end{array}$ & $\begin{array}{l}\tilde{N} \\
\tilde{z}\end{array}$ \\
\hline in & $\begin{array}{l}\hat{0} \\
0^{\prime}\end{array}$ & $\begin{array}{l}\overrightarrow{0} \\
0\end{array}$ & $\overrightarrow{ \pm}$ & $\begin{array}{l}\tilde{U} \\
\tilde{O}\end{array}$ & $\begin{array}{l}\tilde{m} \\
\tilde{0}\end{array}$ & $\begin{array}{l}2 \\
0 \\
0\end{array}$ & $\begin{array}{l}0 \\
+ \\
0 \\
0\end{array} \mid$ & $\begin{array}{l}0 \\
0 \\
0\end{array} \mid$ & $\begin{array}{l}\hat{0} \\
0\end{array}$ & $\stackrel{\simeq}{\simeq}$ \\
\hline$\nabla$ & $\begin{array}{l}1 \\
0 \\
0\end{array}$ & $\begin{array}{l}\sigma_{0} \\
0^{\circ}\end{array}$ & $\begin{array}{l}n \\
0\end{array}$ & $\begin{array}{l}\tilde{N} \\
0\end{array}$ & $\begin{array}{l}\tilde{n} \\
\hat{0}\end{array}$ & $\begin{array}{l} \pm \\
0 \\
0\end{array}$ & 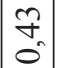 & $\begin{array}{l}0 \\
0 \\
0\end{array}$ & $\begin{array}{l}0 \\
0 \\
0\end{array}$ & $\begin{array}{l}\text { I } \\
0 \\
0\end{array}$ \\
\hline$m$ & $\begin{array}{l}2 \\
\dot{0} \\
0\end{array}$ & $\begin{array}{l} \pm \\
0 \\
0\end{array}$ & $\begin{array}{l}n \\
0\end{array}$ & $\begin{array}{l}0 \\
\text { గn } \\
0\end{array}$ & $\begin{array}{c}\hat{n} \\
\hat{0}\end{array}$ & $\begin{array}{l}n \\
0 \\
0\end{array}$ & $\begin{array}{l}0 \\
+ \\
0 \\
0\end{array}$ & $\begin{array}{l}0 \\
0 \\
0\end{array}$ & $\begin{array}{l}0 \\
0 \\
0\end{array}$ & $\begin{array}{l}n \\
0 \\
0\end{array}$ \\
\hline$N$ & $\begin{array}{c}1 \\
0\end{array}$ & $\begin{array}{l}n \\
0 \\
0\end{array}$ & స్ & 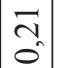 & $\vec{F}_{0}$ & $\begin{array}{l}\tilde{O} \\
0 \\
0\end{array}$ & $\stackrel{\tilde{f}}{+}_{0}$ & $\begin{array}{l}2 \\
0 \\
0\end{array} \mid$ & $\begin{array}{l}1 \\
0 \\
0\end{array} \mid$ & $\begin{array}{l}2 \\
0 \\
0\end{array}$ \\
\hline- & 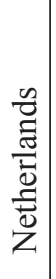 & 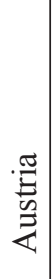 & $\mid \begin{array}{l}\vec{Z} \\
\vec{\Xi} \\
\bar{O} \\
2\end{array}$ & 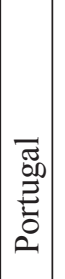 & 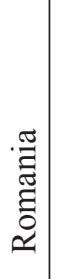 & $\mid \begin{array}{c}\cdot \frac{\pi}{J} \\
\frac{0}{D} \\
\frac{0}{\sim}\end{array}$ & $\left|\begin{array}{l}\frac{\pi}{\sqrt{n}} \\
\frac{\pi}{2} \\
\frac{0}{\sqrt{n}}\end{array}\right|$ & 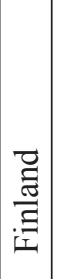 & 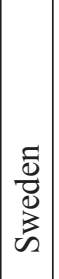 & 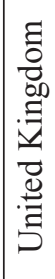 \\
\hline
\end{tabular}




\section{References}

1. Bobeva, D. (2013), The new EU Macroeconomic Imbalances Procedure and its Relevance for the Candidate Countries, Journal of Central Banking Theory and Practice 2(1), Central Bank of Montenegro

2. Borio. C., M. Drehmann (2009), Assessing the risk of banking crises revisited, BIS Quarterly Review, March 2009

3. Csortos, O., Z. Szalai (2013), Assessment of macroeconomic imbalance indicators, MNB Bulletin, 2013, Vol. 8, Issue 3, pp 14-24

4. Davis, E.P., D. Karim (2008), Comparing early warning systems for banking crises, Journal of Financial Stability, Vol. 4, June, pp 89-120

5. European Commission (2011), Scoreboard for the surveillance of macroeconomic imbalances: envisaged initial design /Commission Staff Working Document/

6. European Commission (2015), Adding employment indicators to the scoreboard of the Macroeconomic imbalance procedure to better capture employment and social developments /Commission Staff Working Document/

7. European Parliament (2014), Report on the European Semester for economic policy coordination: implementation of 2014 priorities

8. Hickey, R., L. Kane (2014), Ireland and the Macroeconomic Imbalance Procedure, Central Bank of Ireland, Quarterly Bulletin 03/July 14

9. Regulation (EU) No 1176/2011 of 16 November 2011 on the prevention and correction of macroeconomic imbalances 